\title{
Constancy of pressure-rate product in pacing-induced angina pectoris
}

\author{
Dennis V. Cokkinos and Eutychios M. Voridis \\ From the 2nd Professorial Medical Unit, Evangelismos Hospital, and the Department of Cardiology, King Pau \\ Hospital, Athens, Greece
}

The pressure-rate product during anginal pain produced by right atrial pacing was studied in 12 patients before, during, and after an angiotensin infusion sufficient to produce a significant rise in blood pressure. During the infusion the pain occurred at a significantly lower heart rate $(P<0.001)$. However, the pressurerate product was similar during anginal pain before and during the angiotensin-induced hypertension and after it wore off. Our studies support the concept that in each individual there is a constant level of myocardial oxygen consumption, as expressed by the pressure-rate product, at which anginal pain occurs.

Constancy of the pressure-rate product (heart rate $x$ systolic blood pressure) or the triple product (heart rate $\times$ systolic blood pressure $\times$ ejection time) at the onset of exercise-induced pain has been observed in patients with exertional angina (Robinson, 1967; Redwood et al., 1971). Both 'products' reflect myocardial oxygen consumption $\left(\mathrm{MVO}_{2}\right)$. The duration of the ejection time is now thought to be of minor importance in estimating $\mathrm{MVO}_{2}$. The tension-time index has been found to correlate less well with $\mathrm{MVO}_{2}$ than the pressure-rate product or just the heart rate (Monroe, 1964; Kitamura et al., 1972; Sheffield and Roitman, 1973; Nelson et al., 1974).

It has been shown that with either exercise or atrial pacing patients develop ischaemic manifestations at a constant tension-time index (Sowton et al., 1967; Bahler and Macleod, 1971) or pressure-rate product (O'Brien et al., 1969). We have further investigated the constancy of the pressure-rate product in patients who developed anginal pain with rapid right atrial pacing.

\section{Patients and methods}

Twelve patients were studied. All had developed anginal chest pain in response to rapid right atrial pacing performed by the usual technique (Sowton et al., 1967; Kelemen et al., 1973). Atropine was given to three patients to reverse second degree atrioventricular block occurring at lower heart rates (Cokkinos et al., 1973). All were premedicated with 5 to $10 \mathrm{mg}$ diazepam intra-

Received 30 June 1975. muscularly. Blood pressure during the test was directly recorded in eight patients through an indwelling needle in the brachial artery and measured by a cuff sphygmomanometer in the remaining four patients. The pressurerate product at the onset of pain was calculated in $\mathrm{mmHg} / \mathrm{min}$ (Sheffield and Roitman, 1973) $(1 \mathrm{mmHg} /$ $\min =0.133 \mathrm{kPa} / \mathrm{min}$ ).

After pacing in the initial test had been stopped an intravenous infusion of angiotensin $(2.5 \mathrm{mg}$ in 1 litre normal saline) was started together with continuous monitoring of the blood pressure. When the systolic pressure had increased by $20 \mathrm{mmHg}(2 \cdot 7 \mathrm{kPa})$ or more rapid right atrial pacing was repeated and the pressurerate product at the time of anginal pain was noted. After the angiotensin infusion had been stopped and the blood pressure had returned to initial levels pacing was repeated and the pressure-rate product at the onset of anginal pain recorded again. The heart rate, blood pressure, and pressure-rate product at the time of anginal pain before, during, and after angiotensin administration were compared by the paired $t$ test.

Informed consent for the addition of an angiotensin infusion to the usual procedure of diagnostic rapid atrial pacing was obtained from all patients.

\section{Results}

Angiotensin produced the desired increase in systolic blood pressure in all 12 patients (see Table). The cardiac frequency at which each patient developed chest pain was significantly higher before and after the effect of the angiotensin wore off and lower during the infusion $(P<0.001)$. Thus, though there was a large rise in systolic pressure during angiotensin infusion, the fall in heart rate 
TABLE Heart rate, blood pressure, and pressure-rate product at onset of anginal pain in patients subjected to righ atrial pacing before, during, and after angiotensin infusion

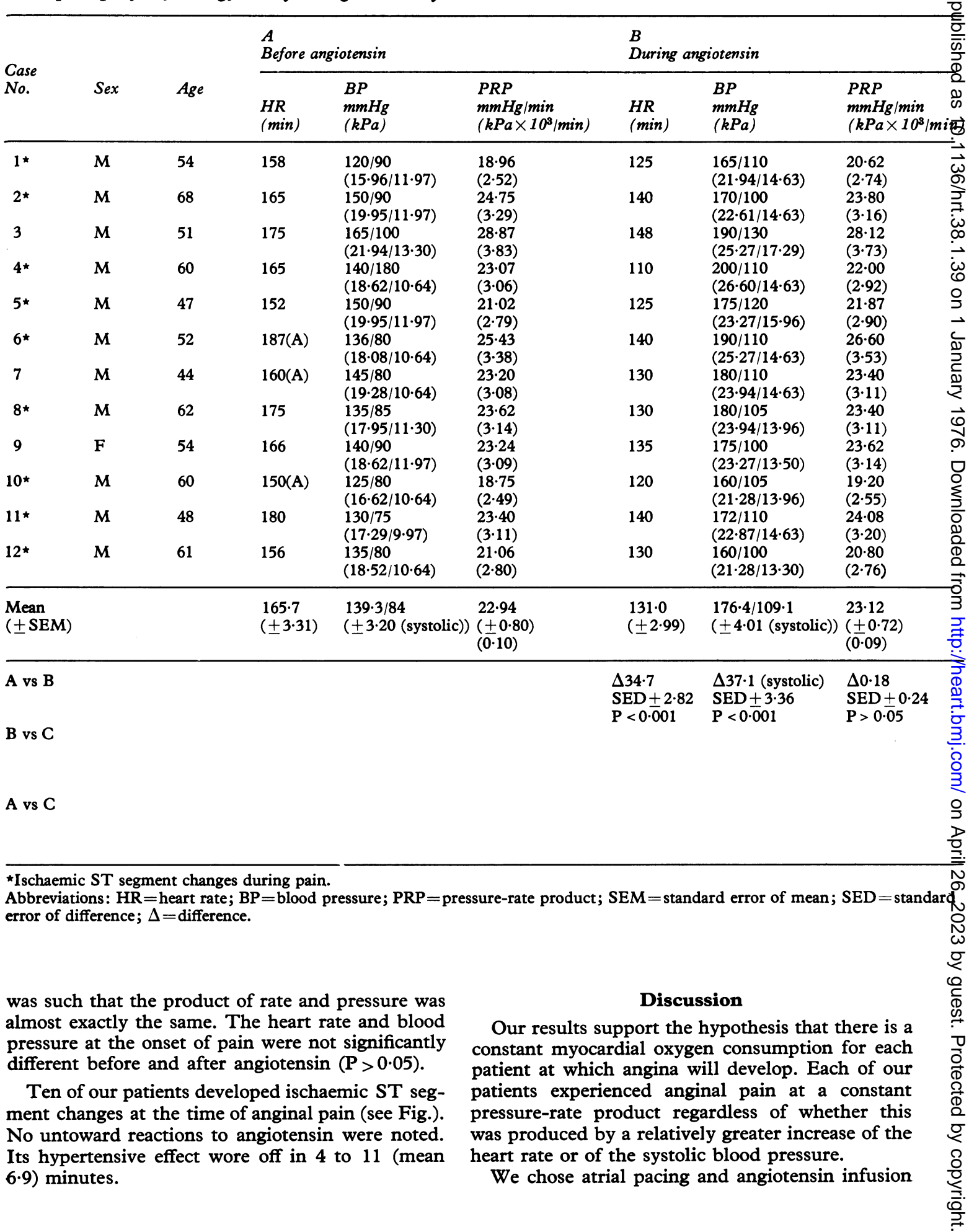




\section{C}

After angiotensin

\begin{tabular}{|c|c|c|c|}
\hline $\begin{array}{l}H R \\
(\min )\end{array}$ & $\begin{array}{l}B P \\
\underset{m m H g}{(k P a)}\end{array}$ & $\begin{array}{l}P R P \\
\operatorname{mmHg} / \min \\
\left(\mathrm{kPa} \times 10^{3} / \mathrm{min}\right)\end{array}$ & $\begin{array}{l}\text { effect ceased } \\
\text { after: } \\
\text { (min) }\end{array}$ \\
\hline 160 & $\begin{array}{l}118 / 80 \\
(15 \cdot 69 / 10 \cdot 64)\end{array}$ & $\begin{array}{l}18 \cdot 88 \\
(2 \cdot 51)\end{array}$ & 5.5 \\
\hline 160 & $\begin{array}{l}150 / 100 \\
(19 \cdot 95 / 13 \cdot 30)\end{array}$ & $\begin{array}{l}24 \cdot 00 \\
(3 \cdot 19)\end{array}$ & $4 \cdot 0$ \\
\hline 170 & $\begin{array}{l}170 / 100 \\
(22 \cdot 61 / 13 \cdot 30)\end{array}$ & $\begin{array}{l}28.90 \\
(3.84)\end{array}$ & 8.5 \\
\hline 170 & $\begin{array}{l}130 / 100 \\
(17 \cdot 29 / 13 \cdot 30)\end{array}$ & $\begin{array}{l}22 \cdot 10 \\
(2 \cdot 93)\end{array}$ & 6.5 \\
\hline 160 & $\begin{array}{l}140 / 95 \\
(18 \cdot 62 / 12 \cdot 63)\end{array}$ & $\begin{array}{l}22 \cdot 40 \\
(2 \cdot 97)\end{array}$ & $10 \cdot 0$ \\
\hline 180 & $\begin{array}{l}140 / 80 \\
(18.62 / 10.64)\end{array}$ & $\begin{array}{l}25 \cdot 20 \\
(3 \cdot 35)\end{array}$ & 11.0 \\
\hline 155 & $\begin{array}{l}148 / 90 \\
(19 \cdot 68 / 11.97)\end{array}$ & $\begin{array}{l}22.94 \\
(3.05)\end{array}$ & $5 \cdot 5$ \\
\hline 180 & $\begin{array}{l}130 / 90 \\
(17 \cdot 29 / 11 \cdot 97)\end{array}$ & $\begin{array}{l}23 \cdot 40 \\
(3 \cdot 11)\end{array}$ & 4.5 \\
\hline 160 & $\begin{array}{l}142 / 85 \\
(19 \cdot 68 / 11 \cdot 30)\end{array}$ & $\begin{array}{l}22 \cdot 72 \\
(3.02)\end{array}$ & 6.5 \\
\hline 150 & $\begin{array}{l}120 / 80 \\
(15.96) / 10.64\end{array}$ & $\begin{array}{l}18.00 \\
(2.39)\end{array}$ & 6.0 \\
\hline 170 & $\begin{array}{l}128 / 70 \\
(17 \cdot 02 / 9 \cdot 31)\end{array}$ & $\begin{array}{l}22.40 \\
(2.97)\end{array}$ & $7 \cdot 0$ \\
\hline 158 & $\begin{array}{l}130 / 75 \\
(17 \cdot 29 / 9 \cdot 97)\end{array}$ & $\begin{array}{l}20.54 \\
(2.73)\end{array}$ & 8.0 \\
\hline $\begin{array}{l}164 \cdot 8 \\
( \pm 2 \cdot 85)\end{array}$ & $\begin{array}{l}137 \cdot 1 / 88 \cdot 7 \\
( \pm 4 \cdot 17 \text { (systoli }\end{array}$ & $\begin{array}{l}22.62 \\
( \pm 0.819)\end{array}$ & 6.9 \\
\hline
\end{tabular}

\begin{tabular}{|c|c|c|}
\hline $\begin{array}{l}\Delta 33.8 \\
S E D \pm 3 \cdot 14 \\
P<0.001\end{array}$ & $\begin{array}{l}\Delta 39 \cdot 3 \\
S E D \pm 2.92\end{array}$ & $\begin{array}{l}\Delta 0.50 \\
S E D \pm 0.31 \\
P>0.05\end{array}$ \\
\hline $\begin{array}{l}\Delta 0.9 \\
\text { SED } \pm 1.06 \\
P>0.05\end{array}$ & $\begin{array}{l}\Delta 2 \cdot 2 \\
S E D \pm 2 \cdot 16 \\
P>0.05\end{array}$ & $\begin{array}{l}\Delta 0.32 \\
S E D \pm 0.30 \\
P>0.05\end{array}$ \\
\hline
\end{tabular}

for manipulating the pressure-rate product for various reasons. Rapid pacing, in contrast to muscular exercise (Piggott et al., 1971), does not produce any significant change in adrenergic activity provided diazepam is given to prevent undue anxiety (Voridis et al., 1974). Nevertheless, Nelson et al. (1974) found that the pressure-rate product correlated very well with $\mathrm{MVO}_{2}$ in exercising patients. We chose angiotensin for raising the blood pressure because, in contrast to sympathomimetic pressor amines, it does not alter myocardial contractility in man (Ross and Braunwald, 1964; Perloff, Binnion, and DeLeon, 1967), though Koch-Weser (1964) and Fowler and Holmes (1964) have described a positive inotropic effect in animals. Moreover, venous tone, venous return, and heart volume, which are considered to influence $\mathrm{MVO}_{2}$ (Simaan, 1974), are only minimally affected by angiotensin (Rose et al., 1962). Patients exercising after nitroglycerin develop anginal pain at a higher pressure-rate product than controls, presumably because of reduced ventricular dimensions, which lower the $\mathrm{MVO}_{2}$. Conversely, after propranolol the pressure-rate product at the onset of angina is reduced, possibly as the result of increased ventricular size, which tends to augment $\mathrm{MVO}_{2}$ (Wolfson, Phillips, and Schecter, 1970; Detry and Bruce, 1971; Goldstein and Epstein, 1973; Nelson et al., 1974).

Angiotensin has been found to increase coronary arterial resistance (Fowler and Holmes, 1964) but Perloff et al. (1967) believed this action to be of no practical significance. Angiotensin has also been used to evaluate contractility in patients with coronary artery disease without any evidence of coronary constrictive effect (Parmley et al., 1975). Anginal chest pain was taken as the criterion of a positive response to atrial pacing. It has been repeatedly stressed that ST segment changes are not specific enough, especially at high atrial pacing rates (Kelemen et al., 1973; Rios and Hurwitz, 1974). Nevertheless, 10 of our 12 patients developed such changes coincidentally with the pain.

Our observations suggested that in addition to other possible haemodynamic modifications drugs preventing increases in blood pressure during exercise may be expected to ameliorate exertional angina.

\section{References}

Bahler, R. C., and Macleod, C. A. (1971). Atrial pacing and exercise in the evaluation of patients with angina pectoris. Circulation, 43, 407.

Cokkinos, D. V., Katsaros, S., Grivas, P., Bakoulas, G., Plessas, S. Tr., and Voridis, E. (1973). Use of atropine for higher right atrial pacing rates. 'Maximal' pacing for diagnosis of coronary artery disease. British Heart fournal, 35, 720.

Detry, J. M. R., and Bruce, R. A. (1971). Effects of nitroglycerin on 'maximal' oxygen intake and exercise electrocardiogram in coronary heart disease. Circulation, 43, 155.

Fowler, N. O., and Holmes, J. C. (1964). Coronary and myocardial actions of angiotensin. Circulation Research, $14,191$.

Goldstein, R. E., and Epstein, S. E. (1973). The use of indirect indices of myocardial oxygen consumption in evaluating angina pectoris. Chest, 63, 302 . 


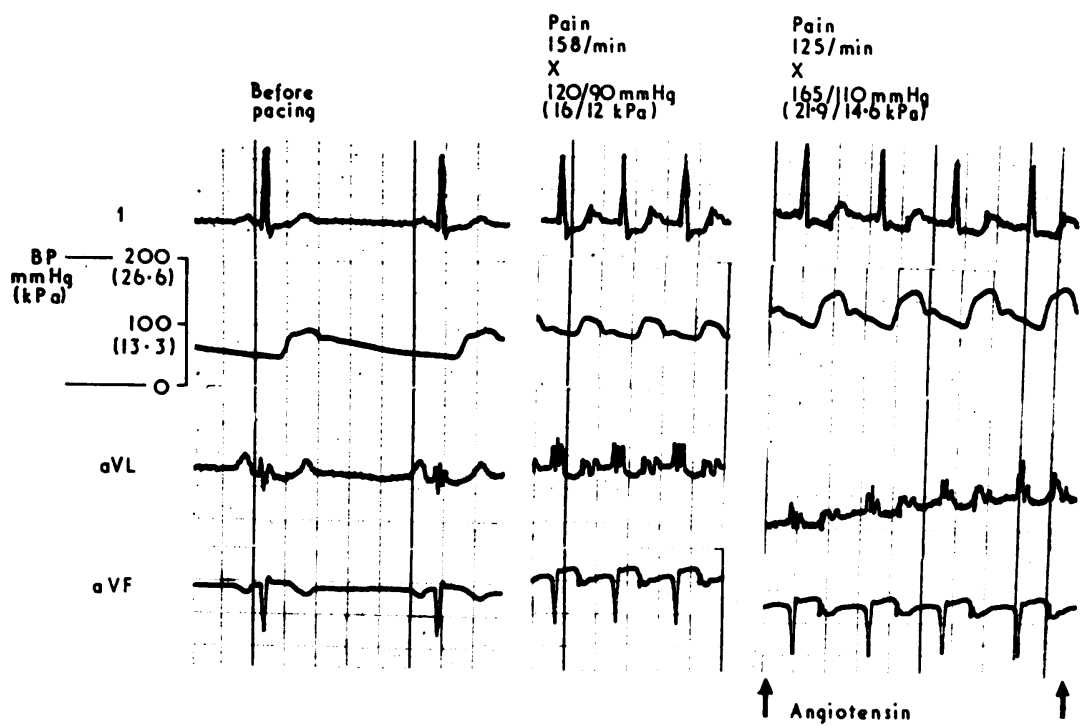

FIG. Case 1. Anginal pain and ischaemic ST changes occur at about the same pressure-rate product before and after angiotensin administration.

Kelemen, M. H., Gillilan, R. E., Bouchard, R. J., Heppner, R. L., and Warbasse, J. R. (1973). Diagnosis of obstructive coronary disease by maximal exercise and atrial pacing. Circulation, 48, 1227.

Kitamura, K., Jorgensen, C. R., Gobel, F. L., Taylor, H. L., and Wang, Y. (1972). Hemodynamic correlates of myocardial oxygen consumption during upright exercise. Fournal of Applied Physiology, 32, 516.

Koch-Weser, J. (1964). Myocardial actions of angiotensin. Circulation Research, 14, 337.

Monroe, R. G. (1964). Myocardial oxygen consumption during ventricular contraction and relaxation. Circulation Research, 14, 294.

Nelson, R. R., Gobel, F. L., Jorgensen, C. R., Wang, K., Wang, Y., and Taylor, H. L. (1974). Hemodynamic predictors of myocardial oxygen consumption during static and dynamic exercise. Circulation, 50, 1179.

O'Brien, K. P., Higgs, L. M., Glancy, D. L., and Epstein, S. E. (1969). Hemodynamic accompaniments of angina. A comparison during angina induced by exercise and by atrial pacing. Circulation, 39, 735.

Parmley, W. W., Tomoda, H., Diamond, G., Forrester, J. S., and Crexells, C. (1975). Dissociation between indices of pump performance and contractility in patients with coronary artery disease and acute myocardial infarction. Chest, 67, 141.

Perloff, J. K., Binnion, R. F., and DeLeon, A. C., Jr. (1967). The use of angiotensin in the assesment of left ventricular function in fixed aortic stenosis. Circulation, 35, 347.

Piggott, V. M., Spodick, D. H., Rectra, E. H., and Khan, A. H. (1971). Cardiocirculatory responses to exercise: physiologic study by noninvasive techniques. American Heart fournal, 82, 632.

Redwood, D. R., Rosing, D. R., Goldstein, R. E., Beiser, G. D., and Epstein, S. E. (1971). Importance of the design of an exercise protocol in the evaluation of patients with angina pectoris. Circulation, 43, 618.

Rios, J. C., and Hurwitz, L. E. (1974). Electrocardiographic responses to atrial pacing and multistage treadmill exercise testing. American fournal of Cardiology, 34, 661.

Robinson, B. F. (1967). Relation of heart rate and systolic blood pressure to the onset of pain in angina pectoris. Circulation, 35, 1073.

Rose, J. C., Kot, P. A., Cohn, J. N., Fries, E. D., and Eckert, G. E. (1962). Comparison of effects of angiotensin and norepinephrine on pulmonary circulation, systemic arteries and veins, and systemic vascular capacity in the dog. Circulation, 25, 247.

Ross, J., and Braunwald, E. (1964). Study of left ventricular function in man by increasing resistance to ventricular ejection with angiotensin. Circulation, 29, 739.

Sheffield, L. T., and Roitman, D. (1973). Systolic blood pressure, heart rate and treadmill work at anginal threshold. Chest, 63, 327.

Simaan, J. (1974). Left ventricular volume as a determinant of myocardial oxygen consumption. Cardiovascular Research, 8, 534.

Sowton, G. E., Balcon, R., Cross, D., and Frick, M. H. (1967). Measurement of the angina threshold using atrial pacing. A new technique for the study of angina pectoris. Cardiovascular Research, 1, 301.

Voridis, E., Trichopoulou, A., Cokkinos, D., Bakoulas, G., Plessas, St., and Miras, K. (1974). Free fatty acid elevation during diagnostic cardiac procedures. Actas del VI Congreso Europeo de Cardiologia 1972, Paz Montalvo, Madrid, p. 827.

Wolfson, S., Phillips, S. L., and Schecter, E. (1970). Effects of specific myocardial beta blockade in angina pectoris. American fournal of Cardiology, 26, 666.

Requests for reprints to Dr. D. V. Cokkinos, 18 Demokritou Street, Athens 136, Greece. 